\title{
THE USE OF ELECTROPALATOGRAPHY IN THE TREATMENT OF SPEECH DISORDERS IN CHILDREN WITH DOWN SYNDROME: A RANDOMISED CONTROLLED TRIAL.
}

Sara E. Wood ${ }^{1}$, Claire Timmins ${ }^{2}$, Jennifer Wishart ${ }^{3}$, William J. Hardcastle ${ }^{1}$ \& Joanne Cleland ${ }^{2}$

${ }^{1}$ Clinical Audiology, Speech and Language Research Centre, Queen Margaret University, Edinburgh

2 School of Psychological Sciences and Health, University of Strathclyde, Glasgow

${ }^{3}$ Moray House School of Education, University of Edinburgh, Edinburgh

Corresponding author:

Dr. Sara Wood

Clinical Audiology, Speech and Language Research Centre

Queen Margaret University

Queen Margaret University Drive

Edinburgh

East Lothian

EH21 6UU

Tel: 01314740000

Fax: 01314740001

Email: swood@qmu.ac.uk

Running head: Intervention for speech errors in Down syndrome

Key words: electropalatography, Down syndrome, intervention, speech production, speech intelligibility

\section{WHAT THIS PAPER ADDS}

In addition to their cognitive disabilities, children and adolescents with Down syndrome present with specific difficulties in speech production which can lead to significantly reduced intelligibility. These difficulties, which are often resistant to change through conventional methods of intervention, can adversely affect academic achievement, social interactions and friendship formation. They typically persist into adulthood, further impacting on social inclusion and putting employment prospects at risk. Speech and language services for older children are often limited despite recent research suggesting that learning can continue throughout adolescence and into adulthood in individuals with Down syndrome. Electropalatography (EPG) is a visual biofeedback technique which has been successfully used to treat intractable speech disorders in a range of clients but there is little published on its 
efficacy for individuals with Down syndrome. This paper demonstrates that some children with Down syndrome can improve their speech production skills when EPG is used in assessment and in intervention.

The positive response to EPG therapy demonstrated here by individual participants suggests that the visual feedback provided by EPG can be a powerful tool in effecting and promoting further speech development in both children and adolescents with Down syndrome. 


\begin{abstract}
Background: Electropalatography (EPG) records details of the location and timing of tongue contacts with the hard palate during speech. It has been effective in treating articulation disorders that have failed to respond to conventional therapy approaches but, until now, its use with children and adolescents with intellectual/learning disabilities and speech disorders has been limited.
\end{abstract}

Aims: This study aimed to evaluate the usefulness of EPG in the treatment of speech production difficulties in children and adolescents with Down syndrome (DS) aged 8-18 years. Methods: Twenty-seven children with DS were assessed on a range of cognitive and speech and language measures and underwent additional EPG assessment. Participants were randomly allocated to one of three age-matched groups receiving either EPG therapy, EPGinformed conventional therapy or 'treatment as usual' over a 12 week period. The speech of all children was assessed before therapy using the Diagnostic Evaluation of Articulation and Phonology (DEAP: Dodd et al. 2002) and re-assessed immediately post- and 3- and 6-month post-intervention to measure percent consonants correct (PCC). EPG recordings were made of the DEAP assessment items at all time-points. Percent intelligibility was also calculated using the Children's Speech Intelligibility Measure (CSIM: Wilcox and Morris 1999).

Results: Gains in accuracy of production immediately post-therapy, as measured by PCC, were seen for all groups. Reassessment at 3- and 6-month post-therapy revealed that those who had received therapy based directly on EPG visual feedback were more likely to maintain and improve on these gains compared to the other groups. Statistical testing showed significant differences between groups in DEAP scores across time-points although the majority did not survive post hoc evaluation. Intelligibility across time-points, as measured by CSIM, was also highly variable within and between the three groups, but despite significant correlations between DEAP and CSIM at all time-points, no statistically significant group differences emerged.

Conclusions and implications: EPG was an effective intervention tool for improving speech production in many participants. This may be because it capitalizes on the relative strength of visual over auditory processing in this client group. The findings would seem to warrant an increased focus on addressing speech production difficulties in current therapy. 


\section{BACKGROUND}

Down syndrome (DS) is the most common genetic cause of learning difficulties, accounting for almost one third of those with moderate to severe learning disability. It is identified in approximately 1 in 1000 to 1100 live births (World Health Organization 2018) and incidence rates, despite screening, are relatively stable. Over 800 babies are born each year in the UK with DS and almost a quarter of a million worldwide.

Children with DS face many developmental challenges. These include persistent delays in expressive language abilities, with these more prevalent than receptive difficulties (Grieco et al. 2015). Speech production problems are often considerably greater than would be anticipated given levels of both general cognitive ability and expressive language skills (Roberts et al. 2007; Naess et al. 2011). Speech production is typically characterized by frequent sound errors, with prolonged use of both developmental phonological processes, for example final consonant deletion, cluster reduction and stopping of fricatives, and atypical phonological processes, for example backing and lateralization (Roberts et al. 2005; Cleland et al.2010), and inconsistent whole word productions (Dodd and Thompson 2001). Errors in speech production are often attributed to structural anomalies but severity has been shown to be more directly related to difficulties in speech motor control, dysarthria and hypotonia (Kent and Vorperian 2013; Rupela, Velleman and Andrianopoulos 2016). In their review of speech impairments in DS, Kent and Vorperian (2013) highlight that articulatory errors frequently involve consonants. Sommers et al. (1988) found the most frequently misarticulated speech sounds in a group of individuals with DS aged 15 to 22 -years were /s/, /d/,/ t /, /r/, /z /, / / /, /s/ clusters, /r/ clusters, /n/, and /v/.

Difficulties in speech production can lead to significantly reduced intelligibility (Kumin 2006; Namasivayam et al. 2013). This affects between $59 \%$ and $95 \%$ of those with DS (Kumin 2006). Percentage of intelligible words produced by children with DS are variably reported but Rupela et al. (2016), in a study of seven children aged between 3;04 and 8;11, reported a range of between $26 \%$ and $89 \%$ compared to $91-99 \%$ for typically developing (TD) children between 2;11 and 5;01. Wild et al. (2018) also found a difference between male and female speakers in a word identification task. They reported that whilst lay listeners correctly identified more than $40 \%$ of words produced by females with DS by age 9 , male speakers did not reach this level until age 16. TD children were fully intelligible by around 6 years of age, again with females showing an age advantage.

Variability and inconsistency are also a common feature of speech production in DS (Dodd \& Thomson 2001; Roberts et al. 2005), exacerbating intelligibility problems. For some children at 
least, making themselves understood becomes such an uphill task that spontaneous conversation, even with peers, may become very limited (Wishart et al. 2007). These difficulties adversely affect academic achievement, social interactions and friendship formation (Hitchcock, Harel, McAllister Byun 2015; Rvachew and Folden 2017). Full inclusion in society and later employment prospects are also potentially at risk (Carr 2008; Kumin and Schoenbrodt 2016).

In order for children and adolescents with DS to reach their full potential, interventions targeting speech at all stages of development are required. Despite evidence that expressive language learning can continue into adolescence (Chapman, Hesketh and Kistler 2002), services for older children are often limited, perhaps due to assumptions about a critical period for language development and a view that learning plateaus in adolescents with intellectual disability (Terband et al. 2018). A study by Rvachew and Folden (2017), however, which provided intervention targeting speech production for a single adolescent with DS, found measurable improvements in accuracy, with parents additionally reporting improvements in intelligibility. Terband et al. (2018) reported improved intelligibility following intervention in a group of adults with intellectual disability which included eleven individuals with DS. This supports the view that learning can continue throughout adolescence and into adulthood in individuals with DS.

Despite this evidence of continuing improvement in speech in later childhood, Dyke et al. (2007) reported that access to SLT services outside of school declines in the teenage years, with both families and professionals dissatisfied with the amount of therapy available. Meyer, Theodoros and Hickson (2017) explored the provision of SLT services in Australia for people with DS across the lifespan and found that the majority of services were offered to younger children, specifically under the age of 7, with 13-17 year olds being identified as the least serviced group. Despite articulation and speech intelligibility being addressed by more than half the SLTs working with school-aged clients, these areas were also identified as needing yet further additional services.

Speech errors in DS are often considered to be intractable as they have typically proved resistant to conventional methods of intervention delivered by SLTs (Gibbon et al. 2003; Kumin, 2006). Alternative treatment approaches that can better address the needs of this population clearly merit exploration. Recent research suggests that speech therapy using visual biofeedback (VBF) can provide an alternative approach to the remediation of persistent speech sound disorders in a number of clinical populations (Hitchcock et al. 2017). Research exploring VBF with individuals with DS is limited. Fawcett, Bacsfalvi and Bernhardt (2008) utilized ultrasound VBF in three young adults with DS to remediate errors in the production of $/ r /$. 
Whilst all participants were reported as beginning to use / $r$ / in words after 13 or 14 sessions this progress was lost when VBF was removed, suggesting problems with long-term generalisation. This is perhaps not surprising given that $/ r /$ is a late acquired and articulatorily complex consonant and known to be particularly vulnerable to problems with generalisation (Preston et al. 2016).

The study to be reported here utilised electropalatography (EPG) to assess and treat speech errors in children and adolescents with DS, using a parallel-group randomized controlled design. EPG is a VBF technique which records the timing and location of tongue contact with the hard palate during continuous speech.

EPG has been applied in research for both assessment and intervention of speech sound disorders in a range of clients, including cleft palate, hearing impairment, dysarthria and DS (for a bibliography of EPG studies see Gibbon 2013). In particular, this technique has been successful in resolving persistent speech errors involving lingual consonants, especially in individuals whose difficulties were considered to be motor-based (Wood and Hardcastle 2000; Gibbon and Wood 2003; Cleland et al. 2009; Wood et al. 2009). Until now, however, the use of EPG with those with a learning disability and a speech disorder has been limited to case studies (Gibbon et al. 2003; Hamilton 1993; Wood et al. 2009). Given the agreement in the literature that those with DS demonstrate motor speech difficulties (Kent and Vorperian 2013; Rupela, Velleman and Andrianopoulos 2016), and that nine of the ten most frequently misarticulated sounds identified by Sommers et al. (1988) involve lingual articulation, a VBF technique such as EPG would seem to offer a well-tailored alternative to traditional auditory-based therapy. EPG has minimal cognitive and language demands and also capitalizes on the known relative strength of visual versus auditory processing ability in children with DS (see e.g. Fidler \& Nadel 2007; Ringenbach et al. 2012). Weismer, Yunusova and Bunton's (2012) suggestion that tongue control is strongly related to speech intelligibility further strengthens the argument for exploring the utility of a VBF technique to target lingual errors in children with DS.

EPG requires the speaker to wear a dental plate (see Figure 1), similar to an orthodontic brace, which fits snugly against the hard palate (Gibbon and Wood 2010). Embedded into the dental plate are 62 electrodes whose position is registered on a computer screen when the tongue touches them. EPG is a particularly valuable diagnostic tool because it gives objective and detailed analysis of an individual's articulation patterns and may identify errors which cannot be detected by perceptual analysis alone but may be vital for accurate diagnosis and effective intervention (Wood and Hardcastle 2000). In addition to providing vital diagnostic information, EPG can be used in therapy to enable the speaker to visualise their tongue contact with the hard palate in real time, providing otherwise inaccessible information which can be used to 
correct erroneous motor programmes. The speech and language therapist (SLT) selects a target articulation pattern characteristic of a particular sound currently being incorrectly produced and displays this on a computer screen. During the therapy session, the client attempts to copy this correct articulation by monitoring their own contact patterns in real time (see Figure 2).

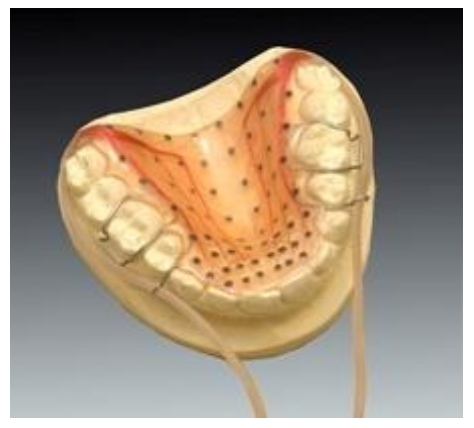

Figure 1: EPG palate on dental cast

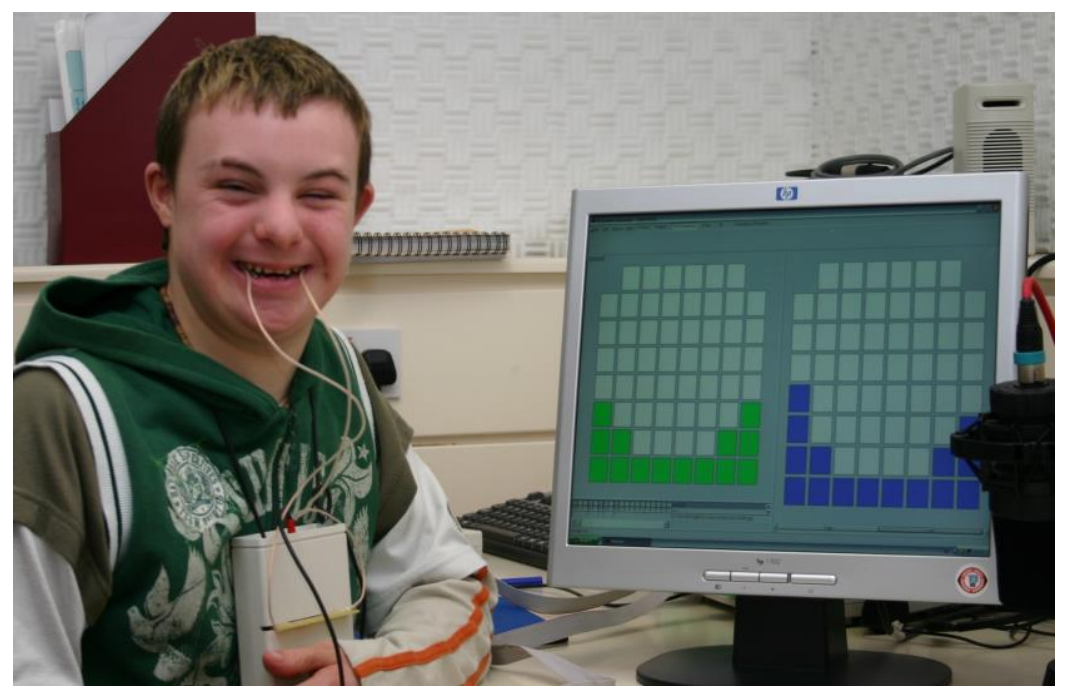

Figure 2: A client attempts to copy the target articulation which is displayed on the right-hand side of the computer screen. The left-hand pattern is the client's attempts to match the target.

\section{AIMS}

This research aimed to evaluate both the efficacy and effectiveness of EPG-based and EPGinformed therapy in improving speech production in school-aged children with Down syndrome. Given the documented relative strengths in visual processing abilities we predicted that those receiving EPG-based therapy would make greater progress over the intervention and follow-up period than those receiving therapy that was only EPG-informed. Given the additional information offered by EPG assessment it was predicted that progress in both these groups would exceed that made by a 'treatment as usual' group. 


\section{METHODS AND PROCEDURES}

\section{Participants}

Children with DS aged 8-18 years were recruited to the project primarily from a participant database already held by one of the authors but also with help from the Scottish Down's Syndrome Association and NHS colleagues. All participants were required to present with errors involving linguapalatal consonants and to have a minimum age-equivalent cognitive level of 3 years. Additional inclusion criteria were: (i) English as a first language, (ii) ability to produce at least single words, (iii) no significant hearing loss (aided threshold $>40 \mathrm{~dB}$ ), (iv) no co-morbid diagnosis of autism, and ( $v$ ) no pacemaker fitted (a precautionary measure as any possible cross-interference between pacemaker and EPG use had not yet been clinically evaluated).

Fifty-seven families were initially approached. Fourteen were not interested in participating, lived too far away to make participation feasible, or anticipated family or school difficulties in committing to 12 weeks of clinic-based therapy sessions. The 43 remaining families were either visited or made a preliminary visit to the clinic. In 9 cases the child failed to meet the full inclusion criteria detailed above, in 5 there were other grounds for withdrawing at an early stage (e.g. palate suitability issues, work commitments, transport difficulties), and in 2 reasons for withdrawing were not given by families.

Twenty-seven children and young people with DS living in the central belt of Scotland were finally recruited to the study, 16 boys and 11 girls. Participants were aged between 8 years 3 months and 18 years 9 months (mean 13 years 5 months, SD 3 years 1 month). None of the participants had previously undergone EPG assessment or intervention.

\section{Ethical approval}

Full ethical approval for recruitment procedures and the study design was granted by the NHS Lothian Research Ethics Committee and Queen Margaret University Research Ethics committee.

\section{Assessment battery}

All children initially completed a battery of standardised speech, language and cognitive assessments and a series of EPG-based assessments of speech production. Speech and language tests were carried out by a qualified speech and language therapist (SLT) and cognitive assessments were carried out by a child psychologist, with each blind to outcomes from the other assessment arm. Most children completed the test battery in three, one-hour sessions, with breaks as requested by either the child or their carer. 
The pre-therapy assessment battery included the following:

Cognitive Ability: Wechsler Preschool and Primary Scale of Intelligence (WPPSI-IIIUK: Wechsler 2003) - verbal and performance age equivalent $\left(\mathrm{AE}^{*}\right)$ scores reported.

Receptive vocabulary: British Picture Vocabulary Test (BPVS II: Dunn et al. 1997) - AE scores reported.

Receptive and Expressive language: Clinical Evaluation of Language Fundamentals Preschool (CELFP-UK, Wiig, Secord \& Semel 1992) - receptive and expressive language AEs reported.

Oromotor Function: Clinical Assessment of Oropharyngeal Motor Development in Young Children (Robbins \& Klee 1987) - structure and function of the vocal tract (including diadochokinesis - DDK) scored as either adult-like (2 points), approaching adult-like (1 point) or absent (0); raw scores converted to percentages.

Speech production: Phonology subtest of Diagnostic Evaluation of Articulation and Phonology (DEAP: Dodd et al. 2002) - percentage consonants correct (PCC) reported.

Intelligibility: Children's Speech Intelligibility Measure (CSIM: Wilcox \& Morris 1999 - chosen because many participants spoke in only single words or short phrases) - percentage of correctly-identified words reported by an adult listener unfamiliar with the child.

(*AEs calculated as test norms based on younger, typically-developing children.)

The DEAP and CSIM data served as baseline data against which therapy outcomes were to be measured. The first assesses accuracy of individual speech sounds whereas the second assesses intelligibility at single word level. The CSIM requires the child to imitate 50 words produced by the SLT which are then played to an unfamiliar adult listener. The imitated words are chosen at random from a choice of $\mathbf{2 0 0}$ word lists. The listener has to choose, from a list of twelve similar sounding words, the item they hear. The number of correctly identified words is multiplied by two to give a percentage of intelligibility. Given the extended period of the study it was not possible to use the same adult listener throughout. All four adult listeners were qualified SLTs and were allocated to participant recording sequentially as each replaced the other over the course of the study. Both the DEAP and the CSIM were re-administered to all groups immediately post-therapy, with these two measures taken again 3 and 6 months later. As before, testing was spread over as many sessions as individual circumstances dictated, typically 1-2 at these later time-points.

During administration of the DEAP, all children wore an EPG palate. To ensure speech production was not audibly affected, each child was required to wear the palate for a total of 24 hours over a one-week period prior to assessment to ensure that they had become accustomed to the feel of the palate in the mouth (McAuliffe, Robb, \& Murdoch 2007). All DEAPs were audio recorded and were transcribed using broad phonetic transcription by a SLT blind to outcomes from other assessment measures and groupings. CSIMs were similarly blind rated. 
To check reliability of DEAP transcriptions, 50 words from four participants ( 200 words in total) were selected at random and transcribed by a different SLT, with transcriptions then compared on a segment-by-segment basis. Mean agreement was $88.2 \%$ ranging from $85.6 \%$ to $90.6 \%$ across the four speakers.

\section{Design}

A single-blinded, parallel RCT design was adopted. A sequence was generated using a random number generator in Excel to allocate participants to one of three groups, two therapy groups and one control group. Allocation concealment was through use of opaque envelopes which were handed to the SLT on completion of the assessment battery. As recruitment to groups progressed age-spread within each group was monitored to ensure the three groups were broadly equivalent, but no adjustment to group was required.

A wide range of speech errors was seen in each group, both developmental and nondevelopmental phonological processes, articulation errors and increased variability of productions. Errors from the first 15 children recruited to the study are described in detail in Cleland et al. (2009), the remaining children showed a similar range of errors. Children in Group 1 received EPG therapy whereas those in Group 2 received speech therapy based on current practice. The same SLT delivered the therapy to both groups. The EPG assessment (also administered by the treating SLT) provided additional objective information that would not usually be available. This allowed the SLT to identify speech errors not detected through auditory analysis alone and set therapy targets accordingly for both groups. Children in Group 3 received no therapy within this study, thereby acting as a control group for maturational gains. The management of participants in Group 3 continued as usual outside of the study as they did for Groups 1 and 2. Those who had been allocated to Groups 2 and 3 were offered EPG therapy following completion of the study.

Table 1 provides a summary of all standardised assessment results for all participants by group at the pre-therapy stage. A one-way analysis of variance revealed no statistically significant group differences in either DEAP or CSIM scores at $p<0.05$ : $F(2,24)=0.538, p=0.591 ; F(2,24)=0.501$, $p=0.613$ respectively. 


\begin{tabular}{|c|c|c|c|c|c|c|c|c|c|c|c|}
\hline & \multirow[b]{2}{*}{ Participant } & \multirow[b]{2}{*}{ Age } & \multirow[b]{2}{*}{ Sex } & \multirow{2}{*}{$\begin{array}{l}\text { DEAP } \\
\text { PCC }\end{array}$} & \multirow{2}{*}{$\begin{array}{c}\text { CSIM } \\
\%\end{array}$} & \multirow{2}{*}{$\begin{array}{c}\text { BPVS-II } \\
\text { AE }\end{array}$} & \multicolumn{2}{|c|}{ CELFP-UK } & \multirow[b]{2}{*}{ RK } & \multicolumn{2}{|c|}{ WPPSI-IIIUK } \\
\hline & & & & & & & CELF-R & CELF-E & & VMA & PMA \\
\hline \multirow{9}{*}{ 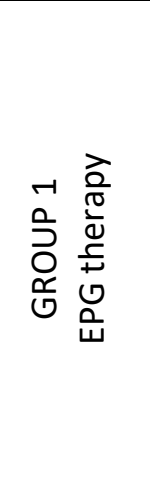 } & DS1 & $9 ; 10$ & $M$ & 59 & 66 & $5 ; 06$ & $4 ; 09$ & $4 ; 00$ & 84.62 & $4 ; 08$ & $5 ; 09$ \\
\hline & DS2 & $10 ; 01$ & $M$ & 38 & 32 & $3 ; 00$ & $3 ; 05$ & 2;09 & 66.35 & $3 ; 11$ & $4 ; 05$ \\
\hline & DS3 & $10 ; 02$ & M & 66 & 84 & $6 ; 10$ & $3 ; 10$ & $4 ; 05$ & 90.38 & $<4 ; 00$ & $>5 ; 05$ \\
\hline & DS4 & $10 ; 11$ & $M$ & 70 & 66 & $5 ; 02$ & $4 ; 02$ & $3 ; 06$ & 81.73 & $>5 ; 01$ & $>5 ; 09$ \\
\hline & DS5 & $11 ; 07$ & $\mathrm{~F}$ & 67 & 72 & $5 ; 05$ & $3 ; 11$ & $3 ; 00$ & 79.81 & $4 ; 08$ & $6 ; 04$ \\
\hline & DS6 & $14 ; 10$ & $M$ & 70 & 46 & $5 ; 02$ & $3 ; 07$ & $3 ; 10$ & 88.46 & $4 ; 03$ & $>6 ; 05$ \\
\hline & DS7 & $14 ; 11$ & $M$ & 59 & 46 & 7;03 & $4 ; 10$ & 4;00 & 69.23 & $5 ; 07$ & $>7 ; 02$ \\
\hline & DS8 & $15 ; 09$ & $\mathrm{~F}$ & 83 & 80 & $4 ; 08$ & 4.02 & $3 ; 01$ & 85.58 & $4 ; 08$ & $>7 ; 01$ \\
\hline & DS9 & $18 ; 09$ & M & 81 & 81 & 4;03 & $4 ; 00$ & 3;05 & 81.73 & $5 ; 03$ & $<4 ; 01$ \\
\hline \multirow{9}{*}{ 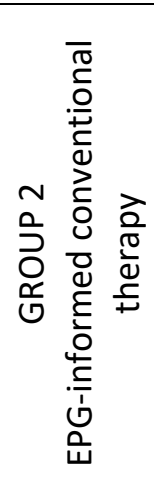 } & DS10 & $8 ; 03$ & $\mathrm{~F}$ & 63 & 50 & $4 ; 00$ & $3 ; 03$ & $2 ; 10$ & 63.46 & $<4 ; 01$ & $<4 ; 03$ \\
\hline & DS11 & $9 ; 02$ & $\mathrm{~F}$ & 82 & 72 & 5;11 & $4 ; 02$ & 5;02 & 79.81 & $5 ; 09$ & $5 ; 10$ \\
\hline & DS12 & $10 ; 05$ & $M$ & 73 & 82 & 5;05 & $4 ; 02$ & 3;08 & 80.77 & $4 ; 05$ & $<5 ; 08$ \\
\hline & DS13 & $13 ; 01$ & $\mathrm{~F}$ & 74 & 80 & $6 ; 06$ & $3 ; 10$ & 3;09 & 81.73 & $5 ; 00$ & $6 ; 03$ \\
\hline & DS14 & $15 ; 06$ & $\mathrm{~F}$ & 78 & 92 & $4 ; 03$ & $3 ; 08$ & $3 ; 03$ & 82.69 & $<4 ; 10$ & $>5 ; 05$ \\
\hline & DS15 & $15 ; 06$ & $M$ & 72 & 54 & $5 ; 10$ & $4 ; 03$ & 3;03 & 72.12 & $5 ; 05$ & $>5 ; 11$ \\
\hline & DS16 & $16 ; 05$ & $M$ & 47 & 43 & 2;11 & 2.09 & 2;06 & 61.54 & $<4 ; 01$ & $<4 ; 06$ \\
\hline & DS17 & $16 ; 06$ & $\mathrm{~F}$ & 33 & 20 & $6 ; 10$ & 4;00 & 3;10 & 51.92 & $5 ; 10$ & $>7 ; 02$ \\
\hline & DS18 & $17 ; 09$ & $\mathrm{~F}$ & 41 & 36 & $2 ; 10$ & - & - & 56.73 & $<4 ; 01$ & $<5 ; 11$ \\
\hline \multirow{9}{*}{ 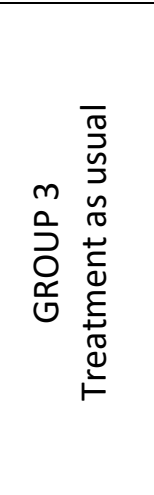 } & DS19 & $9 ; 06$ & $\mathrm{~F}$ & 81 & 82 & $4 ; 04$ & $3 ; 04$ & $3 ; 03$ & 90.38 & $<4.01$ & $<5 ; 04$ \\
\hline & DS20 & 9;06 & $\mathrm{F}$ & 43 & 40 & $3 ; 03$ & $3 ; 03$ & $2 ; 11$ & 72.12 & $<4 ; 01$ & $5 ; 01$ \\
\hline & DS21 & $11 ; 07$ & $M$ & 43 & 38 & $4 ; 08$ & $3 ; 05$ & 3;00 & 61.54 & $<4 ; 01$ & $>6 ; 09$ \\
\hline & DS22 & $13 ; 00$ & $M$ & 87 & 82 & $6 ; 04$ & 4;06 & $4 ; 00$ & 91.35 & $>6 ; 03$ & $>6 ; 09$ \\
\hline & DS23 & $13 ; 10$ & $F$ & 84 & 90 & $5 ; 10$ & $4 ; 04$ & $3 ; 08$ & 79.81 & $5 ; 06$ & $6 ; 01$ \\
\hline & DS24 & $15 ; 08$ & $\mathrm{~F}$ & 40 & - & $3 ; 01$ & $3 ; 01$ & $2 ; 07$ & 68.27 & $<4 ; 01$ & $<5 ; 01$ \\
\hline & DS25 & $15 ; 09$ & $\mathrm{~F}$ & 61 & 37 & $3 ; 03$ & 3;01 & $2 ; 07$ & 70.19 & $<4 ; 01$ & $>6 ; 01$ \\
\hline & DS26 & $16 ; 03$ & $M$ & 54 & 52 & $3 ; 10$ & $3 ; 06$ & $2 ; 10$ & 66.35 & $<4 ; 01$ & $5 ; 02$ \\
\hline & DS27 & $17 ; 05$ & $M$ & 19 & 24 & $3 ; 03$ & $2 ; 10$ & $3 ; 00$ & 54.81 & $<4 ; 01$ & $>7 ; 02$ \\
\hline
\end{tabular}

Table 1: Standardised assessment results for all participants arranged by group.

Key to abbreviations: DEAP: Diagnostic Evaluation of Articulation and Phonology; PCC: percentage consonants correct; CSIM: Children's Speech Intelligibility Measure; BPVS-II: British Picture Vocabulary Scale - II; CELFP-UK: Clinical Evaluation of Language Fundamentals - Preschool UK; CELF-R: CELF Receptive Language; CELF-E: CELF Expressive Language; RK: Robbins and Klee clinical assessment of oropharyngeal motor development in young children; WWPPSI: Wechsler Preschool and Primary Scale of Intelligence; VMA: verbal mental age; and PMA: performance mental age.

Intervention 
For Groups 1 and 2, all therapy was delivered in one hour sessions, twice weekly, over a period of 12 weeks, by the same qualified SLT who had previously undergone training in the use of EPG. The parent or carer was present at each appointment. The SLT first undertook a phonological process analysis of the initial DEAP assessment. Both phonological and phonetic errors were identified and errors that occurred less than 3 times were discounted (Dodd et al. 2002). Therapy targeted speech errors that were considered most disruptive to intelligibility and typically took a developmental approach. For Group 1 this was restricted to lingual mis-articulations as therapy was based on the visual biofeedback provided by EPG; some errors identified by the process analysis could not therefore be targeted. Therapy followed a basic articulatory hierarchy starting with the target phoneme in CV or VC structure using a facilitating vowel (for example using a back vowel for velars) and progressing to other vowels and CVC structures and continuing to more complex word structures. Where progress indicated such, the SLT moved to phrase and sentence level. Since individuals with DS often present with poor phonological awareness and speech perception skills, direct work on speech production was supplemented with some input activities (for more detail see Cleland et al.'s 2009 preliminary report on early entrants to this study). Once a new articulation had been established and was secure in a variety of different contexts, visual feedback was gradually reduced in line with EPG protocol (Gibbon and Wood 2010).

Targets for Group 2 were less constrained and drew on information provided by the EPG assessment. An eclectic approach was adopted, drawing on both input and output activities and more typical of intervention for individuals with specific speech disorders (Joffe and Pring 2008); a core vocabulary approach was taken for those presenting with inconsistent speech productions. Other aspects of speech production such as rate, prosody and loudness were not targeted in either group. Therefore the goals for Group 1 and 2 differed due to constraints imposed by EPG on target selection and treatment methods. For both Groups 1 and 2 the level and dosage of intervention was adjusted to individual participant's needs and abilities and daily home practice of 10-15 minutes each day was recommended. Participants in Group 1 had the use of a portable training unit (PTU) to provide continued visual feedback at home but no record of home practice compliance was recorded for either group.

\section{Statistical Analysis}

In order to evaluate the effectiveness of EPG-based and EPG-informed therapy in improving speech production, the PCC scores from the DEAP assessment and the CSIM scores were investigated across the four time-points: pre-therapy, post-therapy, 3-month post-therapy and 6-month post-therapy.

Following Murray, McCabe and Ballard (2015), comparisons were made from the following time-points to investigate change immediately after intervention and to investigate 
maintenance of gains at later stages: (1) pre-therapy to post-therapy (to assess impact of intervention), (2) post-therapy to 3-month post-therapy (to assess short-term maintenance of any intervention effects), and (3) post-therapy to 6-month post-therapy (to test for longer-term gains).

Post-therapy data were not available for all participants across all measures at all time-points. One participant withdrew from the study prior to all post-therapy assessments, some data points were missing due to clients' cancelling and being unable to reschedule within the planned time frame, and in a small number of cases, irretrievable corruption of data files produced missing cells (see Table 2 ).

\begin{tabular}{|l|c|c|c|c|c|c|c|c|}
\cline { 2 - 9 } \multicolumn{1}{c|}{} & \multicolumn{2}{c|}{ Pre-therapy } & \multicolumn{2}{c|}{ Post-therapy } & \multicolumn{2}{c|}{ 3m post-therapy } & \multicolumn{2}{c|}{ 6m post-therapy } \\
\cline { 2 - 9 } \multicolumn{1}{c|}{} & DEAP & CSIM & DEAP & CSIM & DEAP & CSIM & DEAP & CSIM \\
\hline Group 1 & 9 & 9 & 9 & 9 & 7 & 7 & 9 & 6 \\
\hline Group 2 & 9 & 9 & 9 & 8 & 8 & 8 & 8 & 6 \\
\hline Group 3 & 9 & 8 & 7 & 6 & 6 & 6 & 8 & 4 \\
\hline
\end{tabular}

Table 2: Number of participants at each time-point (maximum $n$ in each group $=9$ )

Due to the small and varying numbers of participants across time-points, Shapiro-Wilks tests of normality were performed on the distribution of the DEAP and CSIM data (see Table 3).

\begin{tabular}{|l|c|c|c|c|c|c|c|c|}
\cline { 2 - 9 } \multicolumn{1}{c|}{} & \multicolumn{2}{c|}{ Pre-therapy } & \multicolumn{2}{c|}{ Post-therapy } & \multicolumn{2}{c|}{ 3m post-therapy } & \multicolumn{2}{c|}{ 6m post-therapy } \\
\cline { 2 - 9 } \multicolumn{1}{c|}{} & DEAP PCC & CSIM & DEAP PCC & CSIM & DEAP PCC & CSIM & DEAP PCC & CSIM \\
\hline Group 1 & .368 & .185 & .028 & .586 & .784 & .039 & .078 & .875 \\
\hline Group 2 & .156 & .368 & .555 & .369 & .328 & .164 & .094 & .875 \\
\hline Group 3 & .454 & .157 & .429 & .588 & .398 & .844 & .664 & .012 \\
\hline
\end{tabular}

Table 3: Shapiro-Wilk's test of normality $p$ values for both measurements at each time-point

As noted in Table 3, data for each measure were not normally distributed in all groups at different time points. A within-groups non-parametric statistical test for repeated measures (Friedman's test) was therefore performed for each group across the 4 time-points. Confidence intervals were set at $95 \%$ with a $p$ value of $<.05$. Post-hoc investigations were performed using Wilcoxon signedrank tests. As this did not allow for a comparison between treatment groups, a Kruskal-Wallis $\mathrm{H}$ test was also applied to investigate group differences. Group comparisons were performed on assessment scores using change scores for each planned comparison (i.e. the post-therapy score minus the pre-therapy, 3-month post-therapy minus post-therapy, 6-month post-therapy minus post-therapy). Post-hoc analysis was performed using Mann-Whitney $U$ tests. 
A Spearman's rank-order correlation was run to investigate the relationship between the DEAP PCC and the CSIM scores over time as previous research has shown a relationship between improvements in PCC and intelligibility (McLeod, Harrison and McCormack 2012).

\section{RESULTS}

Means and standard deviations for DEAP PCC and CSIM scores at each time-point are presented in Table 4.

\begin{tabular}{|c|c|c|c|c|c|c|c|c|c|c|c|c|}
\cline { 2 - 12 } \multicolumn{1}{c|}{} & \multicolumn{3}{c|}{ Pre-therapy } & \multicolumn{3}{c|}{ Post-therapy } & \multicolumn{3}{c|}{3 m post-therapy } & \multicolumn{3}{c|}{6 m post-therapy } \\
\cline { 2 - 13 } \multicolumn{1}{c|}{} & Group & Group & Group & Group & Group & Group & Group & Group & Group & Group & Group & Group \\
& 1 & 2 & 3 & 1 & 2 & 3 & 1 & 2 & 3 & 1 & 2 & 3 \\
\hline DEAP & 65.9 & 62.6 & 56.9 & 76.2 & 72.0 & 61.4 & 77.0 & 66.6 & 65.0 & 80.8 & 70.8 & 66.9 \\
PCC & $(13.4)$ & $(17.8)$ & $(23.3)$ & $(16.4)$ & $(15.7)$ & $(26.4)$ & $(13.3)$ & $(19.5)$ & $(20.1)$ & $(13.4)$ & $(16.0)$ & $(18.5)$ \\
\hline & 63.7 & 58.8 & 55.6 & 67.5 & 56.5 & 54.7 & 57.7 & 60.0 & 45.0 & 69.3 & 60.7 & 56.0 \\
CSIM & $(18.3)$ & $(24.1)$ & $(25.3)$ & $(22.0)$ & $(22.1)$ & $(17.6)$ & $(21.6)$ & $(27.8)$ & $(21.9)$ & $(13.7)$ & $(21.3)$ & $(22.7)$ \\
\hline
\end{tabular}

Table 4: Mean and standard deviation for DEAP PCC and CSIM scores at each time-point for each group.

Table 4 and Figure 3 indicate that all intervention groups showed an increase in DEAP PCC scores from pre- to post-therapy. Group 1 and Group 3 continued to show an increase in DEAP PCC scores at 3-month post-therapy and at 6-month post-therapy. CSIM scores increased only for Group 1 between pre- and post-therapy but this was not maintained at the 3-month posttherapy time-point, although an increase in intelligibility was seen at 6-month post-therapy (Figure 4).

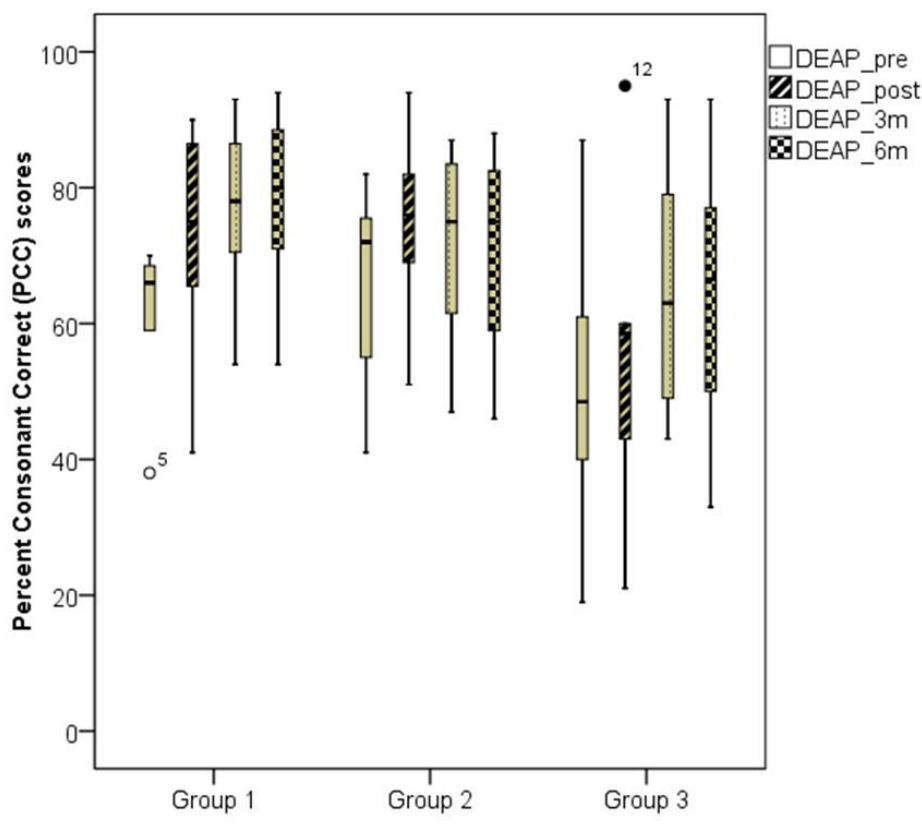


Figure 3: Boxplot showing median and IQR values for the Diagnostic Evaluation of Articulation and Phonology (DEAP) PCC scores for Group 1 (EPG-therapy), Group 2 (EPG-informed conventional therapy) and Group 3 (treatment as usual) across the four time-points.

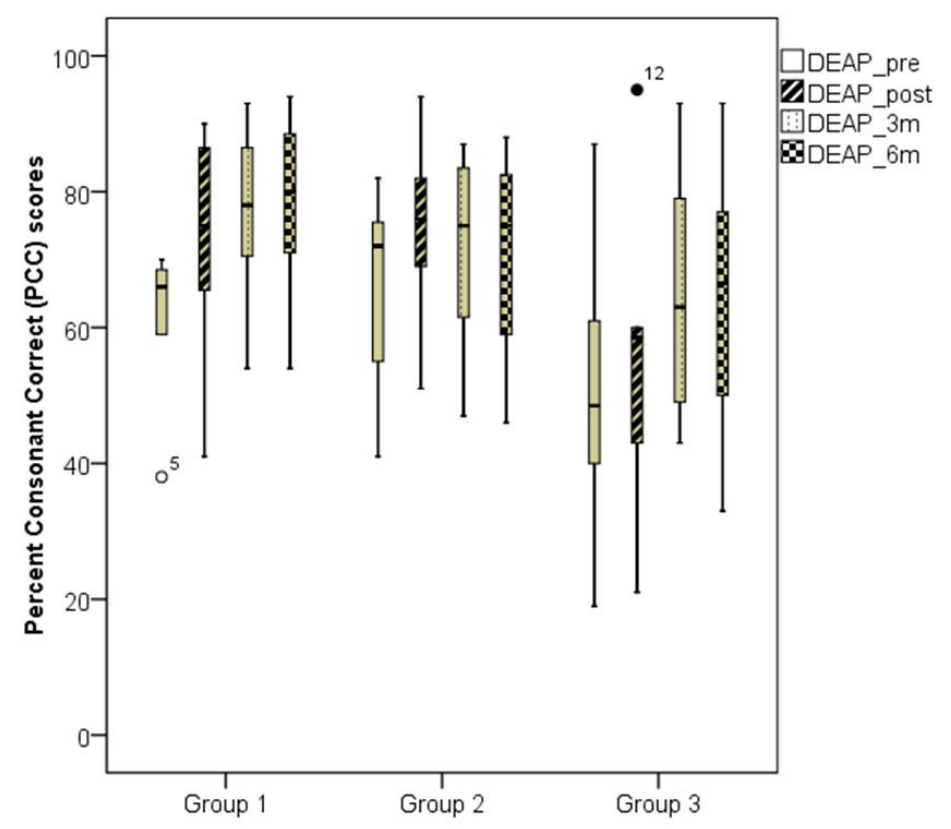

Figure 4: Boxplot showing median and IQR values for the Children's Speech Intelligibility Measure (CSIM) for Group 1 (EPG-therapy), Group 2 (EPG-informed conventional therapy) and Group 3 (treatment as usual) across the four time-points.

\section{Within Group Comparisons}

DEAP PCC scores

A Friedman's test identified a statistically significant difference in DEAP PCC across the four time-points for Group $1, \chi^{2}(3)=14.603, p=.002$. Post-hoc analysis with Wilcoxon signed-rank tests was conducted. Although scores were noted to rise at each subsequent time-point, there were no significant differences between the post-therapy and 3-month post-therapy scores $(Z=$ -1.69, $p=.091)$, nor between the post-therapy and 6-month post-therapy scores $(Z=-1.689$, $p=.091)$. However, there was a statistically significant increase of scores from pre-therapy to post-therapy $(Z=-2.668, p=.008$, effect size (Cohen's $d) r=.63$ ).

Group 2 DEAP PCC scores also showed a statistically significant difference across the timepoints, $\chi^{2}(3)=10.271, p=.017$. Post-hoc analysis identified decreased scores from posttherapy to 3 -month post-therapy but these were not significant $(Z=-1.546, p=.122)$. This was 
the same for the post-therapy and 6-month post-therapy comparison $(Z=-1.262, p=.207)$. However, there was a statistically significant increase of scores from pre-therapy to posttherapy $(Z=-2.670, p=.008$, effect size (Cohen's $d) r=.63)$.

DEAP PCC scores also differed significantly across time-points for Group 3, $\chi^{2}(3)=14.6, p=$ .002. Post-hoc analysis found that none of the time-point comparisons presented as statistically significant: pre-therapy and post-therapy $(Z=-1.992, p=.046)$, post-therapy and 3-month posttherapy $(Z=-1.363, p=.173)$, post-therapy and 6-month post-therapy $(Z=-1.101, p=.271)$.

CSIM scores

None of the group CSIM scores showed a statistically significant difference across the timepoints.

\section{Between Group Comparisons}

DEAP PCC scores

DEAP PCC difference scores from pre- to post-therapy were evaluated using a Kruskal-Wallis $\mathrm{H}$ test which showed that there was no statistically significant difference between intervention groups at this time-point: $\chi^{2}(2)=1.830, p=.401$. The same test was completed for the posttherapy and 3-month post-therapy difference scores. There was a statistically significant difference for groups, $\chi^{2}(2)=6.114, p=.047$, with a mean rank DEAP PCC score of 12.86 for Group 1, 6.81 for Group 2 and 14.42 for Group 3. This difference did not survive post hoc Mann-Whitney $U$ testing which found no significant difference between Group 1 and Group 3 $(U=14.5, p=.366)$, Group 2 and Group $3(U=10, p=.081)$, and Group 1 and Group 2 ( $U=25.0$, $\mathrm{p}=.190)$. A significant difference was noted between groups at the post-therapy to 6-month post-therapy comparison point, $\chi^{2}(2)=6.702, p=.035$, with a mean rank DEAP PCC score of 14.72 for Group 1, 7.25 for Group 2 and 15.64 for Group 3. Post-hoc Mann-Whitney U testing found significant differences between Group 1 and Group $2(U=13.0, p=.027$ with an effect size of (Cohen's d) r= -.42), between Group 2 and Group 3 ( $U=9.0, p=.029$, effect size (Cohen's d) $r=-$ $.42)$, but not between Group 1 and Group $3(U=28.5, p=.75)$.

\section{CSIM scores}

CSIM difference scores were tested in the same way as the DEAP PCC scores above. There was no statistically significant difference between intervention groups, $\chi^{2}(2)=.386, p=.825$ for time-point 1 (pre-therapy vs post-therapy), time-point 2 (post-therapy vs 3-month posttherapy), $\chi^{2}(2)=3.1043, p=.218$, or time-point 3 (post-therapy vs 6 -month post-therapy), $\chi^{2}$ $(2)=1.043, p=.594$. 


\section{Relationship between PCC and intelligibility}

A Spearman's rank-order correlation to investigate the relationship between DEAP PCC scores and CSIM scores over time showed a strong, positive association between the measures at each time point (see Table 5).

\begin{tabular}{|l|l|l|l|l|}
\hline Measure & Pre-therapy & Post-therapy & 3-month post-therapy & 6-month post-therapy \\
\hline $\begin{array}{l}\text { DEAP PCC } \\
* \text { CSIM }\end{array}$ & $r=.799, p<.01$ & $r=.771, p<.01$ & $r=.710, p<.01$ & $r=.753, p<.01$ \\
\hline
\end{tabular}

Table 5: Spearman's rank-order correlation showing the relationship between DEAP PCC and CSIM scores over time.

\section{Maintenance of Gains}

Further investigation of gains was carried out by plotting the differences in group mean DEAP PCC and CSIM mean scores between pre-therapy and each subsequent time-point (pre- to posttherapy, pre- to 3-month post-therapy and pre- to 6-month post-therapy. In Figures 5 and 6, the pre-therapy scores were set to zero for all groups.

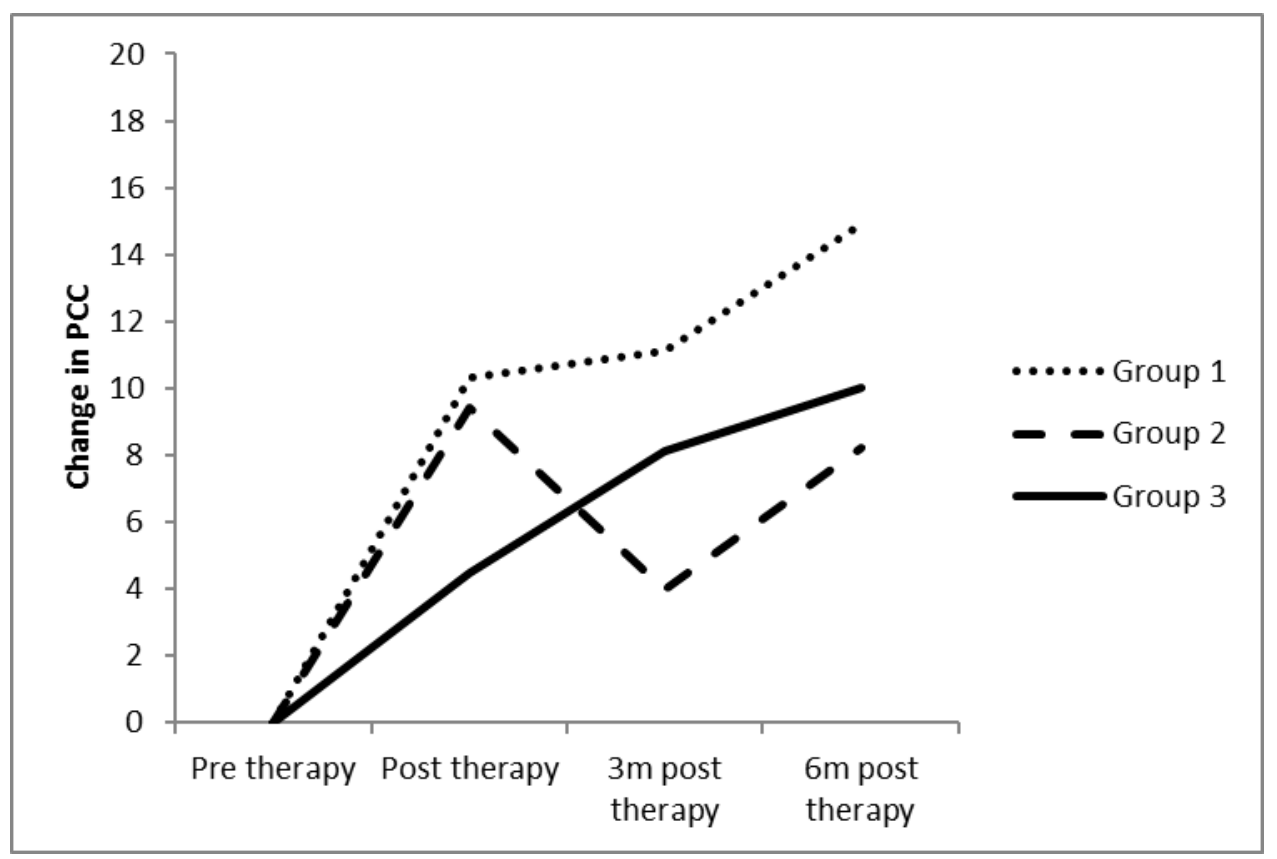

Figure 5: Change in mean DEAP PCC difference scores over time for Groups 1-3

As Figure 5 shows, DEAP PCC difference scores for Groups 1 and 3 presented a similar pattern over time in that gains were seen at all three comparison points. However the gains at posttherapy, at 3-month post-therapy, and 6-month post-therapy were noticeably greater in Group 
1, with Group 3 showing a more linear progression. In contrast, following initial gains from pretherapy to post-therapy, Group 2 gains were not maintained over the following 3 months and despite an uplift in scores between 3- and 6-month post-therapy, overall scores remained lower than those achieved immediately post-therapy, indicating that some of the gains made during therapy had been lost.

In contrast, only Group 1 showed an increase in CSIM scores from pre- to post-therapy. Although mean scores decreased sharply between pre-therapy and 3-month post-therapy, gains were recovered by 6-month post-therapy, resulting in an overall post-therapy gain of 5.6. Groups 2 and 3 both showed an initial small decrease in mean scores between pre- and immediately post-therapy time-points, Group 2 then showing gains at both subsequent comparison points, resulting in a final overall gain of 1.9. Group 3 scores continued to decrease post-therapy, recovering to some extent latterly, but resulting in only a marginal overall gain of 0.4 .

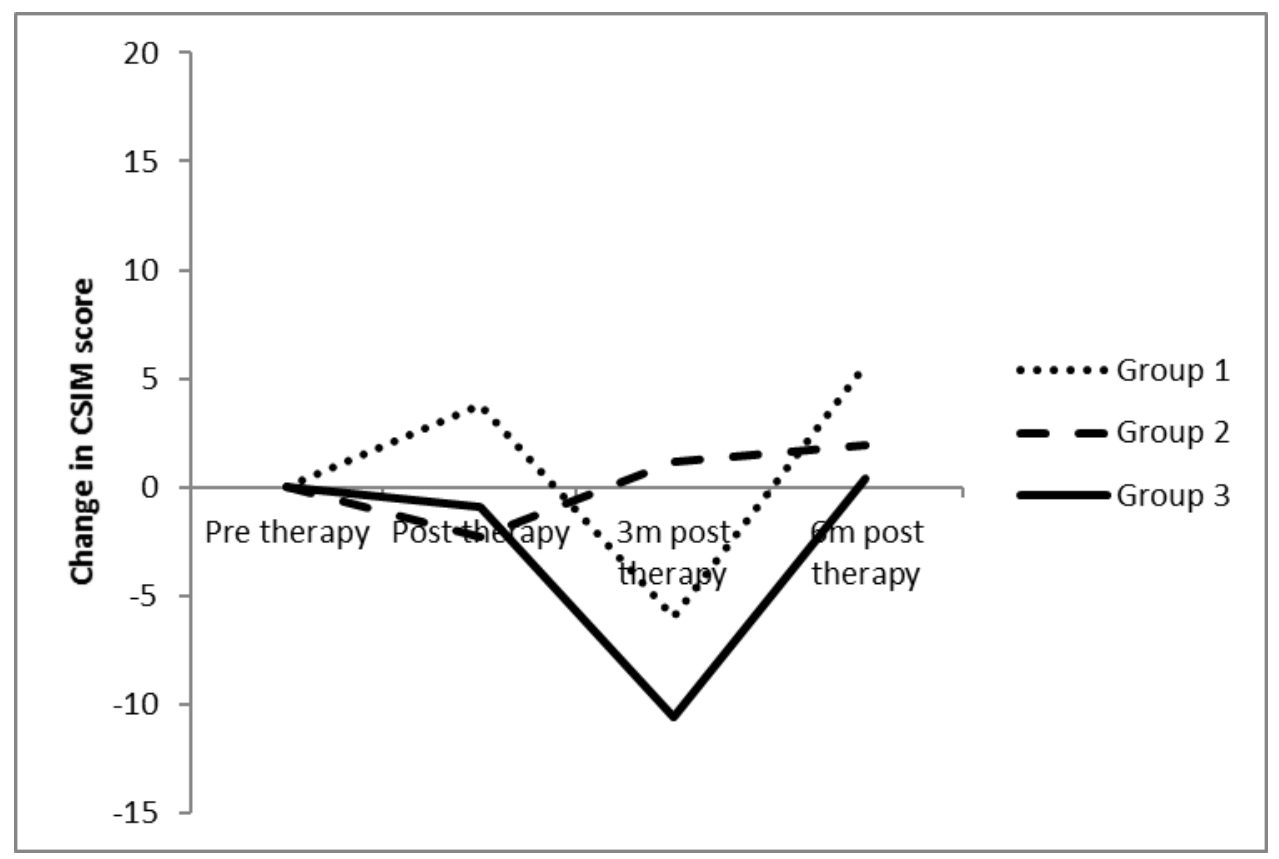

Figure 6: Change in mean CSIM difference scores over time for Groups 1-3

Individual scores

Given the exceptionally high variability in group scores on outcome measures at all 4 time-points (see Table 4), changes in PCC scores were also examined at the individual level to look for any trends across time-points that might not have been statistically detectable due to small numbers and this high variability (see Table 6). CSIM scores were not considered at this level due to the number of missing data points post-therapy. 
From Table 6, it can be seen that all 9 participants in the two therapy groups, Groups 1 and 2, showed improved PCC scores immediately post-therapy; in Group 3, 5 out of the 7 participants for whom data were held also improved on their initial scores at this time-point. In terms of maintenance of these gains, 6 out of 7 Group 1 participants maintained and showed further improvements in PCC scores at the 3-month post-therapy comparison point and 6 at the final, 6 month post-therapy comparison point; total gains over the 9 month of the study ranged between 6 and 28 percentage points in Group 1. In contrast, only 2 out of 8 Group 2 participants maintained and increased scores at the 3-month post-therapy comparison point; overall, 3 out of 8 participants had maintained or increased their PCC scores at the end of the study, but total gains over the 9 months were generally much lower than in Group 1, ranging between 2 and 10 percentage points. Group 3 did not receive therapy as part of the study but 5 out of 7 participants showed improved PCC scores at post-therapy, 4 out of 6 at 3-month post-therapy, and 6 out of 7 at 6-month post-therapy; overall, 7 improved their PCC scores over the course of the study, with gains ranging from 6-23 percentage points. 


\begin{tabular}{|c|c|c|c|c|c|c|c|c|c|}
\hline & & \multicolumn{4}{|c|}{ DEAP PPC scores } & \multicolumn{4}{|c|}{ CSIM scores } \\
\hline & & $\begin{array}{c}\text { Pre- } \\
\text { therapy }\end{array}$ & $\begin{array}{c}\text { Post- } \\
\text { therapy }\end{array}$ & $\begin{array}{l}3 m \text { post- } \\
\text { therapy }\end{array}$ & $\begin{array}{l}6 \mathrm{~m} \text { post- } \\
\text { therapy }\end{array}$ & $\begin{array}{l}\text { Pre- } \\
\text { therapy }\end{array}$ & $\begin{array}{l}\text { Post- } \\
\text { therapy }\end{array}$ & $\begin{array}{l}3 \mathrm{~m} \text { post- } \\
\text { therapy }\end{array}$ & $\begin{array}{l}6 \mathrm{~m} \text { post- } \\
\text { therapy }\end{array}$ \\
\hline \multirow{9}{*}{ 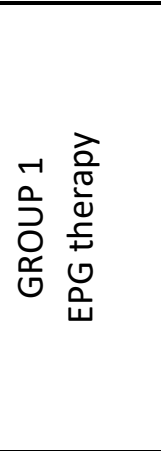 } & DS1 & 59 & $66(+7)$ & $68(+9)$ & $77(+18)$ & 66 & $62(-4)$ & $66(+/-0)$ & $62(-4)$ \\
\hline & DS2 & 38 & $41(+3)$ & $54(+16)$ & $54(+16)$ & 32 & $26(-6)$ & $14(-18)$ & - \\
\hline & DS3 & 66 & $87(+21)$ & $93(+27)$ & $94(+28)$ & 84 & $94(+10)$ & $74(-10)$ & $92(+8)$ \\
\hline & DS4 & 70 & $86(+16)$ & $87(+17)$ & $80(+10)$ & 66 & $78(+12)$ & $74(+8)$ & $64(-2)$ \\
\hline & DS5 & 67 & $75(+8)$ & $78(+11)$ & $89(+22)$ & 72 & $58(-14)$ & $46(-26)$ & $76(+4)$ \\
\hline & DS6 & 70 & $90(+20)$ & $86(+16)$ & $88(+18)$ & 46 & - & - & - \\
\hline & DS7 & 59 & $65(+6)$ & $73(+14)$ & $65(+6)$ & 46 & $54(+8)$ & $60(+14)$ & $52(+6)$ \\
\hline & DS8 & 83 & $88(+5)$ & - & $90(+7)$ & 80 & $82(+2)$ & $70(-10)$ & - \\
\hline & DS9 & 81 & $88(+7)$ & - & $90(+9)$ & 81 & $86(+5)$ & - & $70(-11)$ \\
\hline \multirow{9}{*}{ 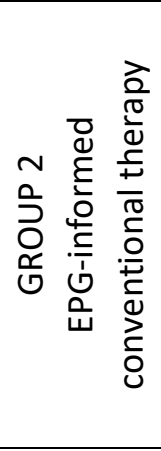 } & DS10 & 63 & $68(+5)$ & $69(+6)$ & $71(+8)$ & 50 & $54(+4)$ & $58(+8)$ & - \\
\hline & DS11 & 82 & $94(+12)$ & $87(+5)$ & $84(+2)$ & 72 & - & - & - \\
\hline & DS12 & 73 & $76(+3)$ & $83(+10)$ & $75(+2)$ & 82 & $84(+2)$ & $90(+8)$ & $74(-8)$ \\
\hline & DS13 & 74 & $85(+11)$ & - & $74(+/-0)$ & 80 & $80(+/-0)$ & - & $94(+14)$ \\
\hline & DS14 & 78 & $85(+7)$ & $84(+6)$ & $88(+10)$ & 92 & $70(-22)$ & $84(-8)$ & $64(-28)$ \\
\hline & DS15 & 72 & $79(+7)$ & $75(+3)$ & $81(+9)$ & 54 & $56(+2)$ & $66(+12)$ & $52(-2)$ \\
\hline & DS16 & 47 & $51(+4)$ & $47(+/-0)$ & $46(-1)$ & 43 & $54(+11)$ & $44(+1)$ & $44(+1)$ \\
\hline & DS17 & 33 & $45(+12)$ & $34(+1)$ & - & 20 & $18(-2)$ & $8(-12)$ & - \\
\hline & DS18 & 41 & $70(+29)$ & $54(+13)$ & $47(+6)$ & 36 & $36(+/-0)$ & $44(+8)$ & $36(+/-0))$ \\
\hline \multirow{9}{*}{ 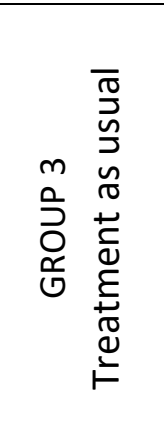 } & DS19 & 81 & - & - & $70(-11)$ & 82 & - & - & - \\
\hline & DS20 & 43 & $43(+/-0)$ & $51(+8)$ & $50(+7)$ & 40 & $58(+18)$ & $54(+14)$ & $46(+6)$ \\
\hline & DS21 & 43 & - & - & - & 38 & - & - & - \\
\hline & DS22 & 87 & $95(+8)$ & $93(+6)$ & $93(+6)$ & 82 & $74(-8)$ & $62(-20)$ & $90(+8)$ \\
\hline & DS23 & 84 & $94(+10)$ & - & $90(+6)$ & 90 & $74(-16)$ & - & - \\
\hline & DS24 & 40 & $59(+19)$ & $49(+9)$ & $60(+20)$ & - & 42 & 10 & 46 \\
\hline & DS25 & 61 & $60(-1)$ & $79(+18)$ & $73(+12)$ & 37 & $40(-3)$ & $42(+5)$ & $42(+5)$ \\
\hline & DS26 & 54 & $58(+4)$ & $75(+21)$ & $77(+23)$ & 52 & $50(-2)$ & $70(+18)$ & - \\
\hline & DS27 & 19 & $21(+2)$ & $43(+24)$ & $33(+14)$ & 24 & $30(+6)$ & $32(+8)$ & - \\
\hline
\end{tabular}

Table 6: Raw DEAP PCC and CSIM scores for each participant at the 3 comparison time-points. Numbers in brackets show gains from pre-to post-therapy, pre- to 3-month post-therapy, and pre- to 6-month post-therapy. 


\section{DISCUSSION}

This study aimed to investigate the use of EPG in the treatment of speech production errors in 27 children and young people with DS. Participants were randomly assigned to one of three age-matched groups, with Groups 1 and 2 receiving clinic-based, bi-weekly therapy over a 12 week period. Therapy for Group 1 directly utilised EPG visual biofeedback, Group 2 received conventional therapy informed by pre-therapy EPG assessment and Group 3 served as the 'treatment as usual' control group. Speech production and intelligibility were assessed in all groups at 4 time-points, over a period of 9 months. As prior single-case studies (Gibbon et al. 2003; Wood et al. 2009) had demonstrated that EPG could successfully resolve persistent speech sound errors in children with DS, it was predicted that progress would be greatest in Group 1 and least in Group 3.

Recent overviews of the field emphasise the need for RCTs of developmental speech and language disorders but it has to be acknowledged that achieving this standard of evidence in practice, in populations of limited size and showing high intra group variability, is always going to be challenging. Although our results did not reach statistical significance this study supports earlier findings that EPG can be a successful intervention technique for children with DS and that on some measures it can be more effective than conventional therapy. Reassessment at 3 and 6-month post-therapy revealed that those who had received therapy based directly on EPG visual feedback were more likely to maintain and improve on these gains compared to those who received EPG-informed conventional therapy or no therapy. This suggests that the VBF afforded by the EPG is a powerful tool in effecting and promoting further speech development.

Despite the rigour of the design, the respectable sample size and the length of the monitoring period, the findings from this study were not straightforward to interpret and in many respects have raised more questions than answers. In terms of statistical analyses, the lack of statistically significant differences between the groups on both PCC and CSIM measures were contrary to expectation. From Table 4 and Figures 3 and 4 , it is evident that the variability in scores was extremely large in all groups and this, plus the unavoidably small sample, inevitably decreased the chances of identifying statistically significant differences post-therapy with outcome measures used here. The gaps in data sets at later time-points also presented obstacles to statistical analyses. Despite the resources and effort being put into the study, these gaps in data collection were perhaps unsurprising, especially in Group 3. All families agreed to take part in our study because of their concerns about their child's speech and as such all hoped to be assigned to one of the therapy arms. For those randomly assigned to Group 3, no clinic-based therapy was on offer and there was therefore not the same incentive to attend subsequent appointments. 
The measures we used to track changes in speech production and intelligibility in each child over 9 months are perhaps worth reconsidering at this point. We used percentage of consonants correctly produced using the phonology subtest of the DEAP. Whilst this is common in clinical and research practice, this measures generalisation in changes in speech production rather than change related to specific therapy targets. The subtest consists of 141 possible consonant productions which cover all English consonants in syllable initial and final position. Each sound targeted in therapy only appears at most twice as a singleton consonant in the assessment (less if the child fails to produce certain words) and some will appear in consonant clusters. Therapy case notes revealed that in Groups 1 and 2, between 1 and 4 sounds were targeted during the 12 weeks of therapy depending on the individual's profile and progress during therapy. Any changes in DEAP scores identified might therefore actually represent quite significant growth. Word lists designed to probe segments in varying phonotactic environments would have provided more detailed information on the areas of speech sound production specifically targeted (see Cleland and Scobbie 2018), however, and should be considered in future studies.

Cleland and Scobbie (2018) have recently brought into question the usefulness of classifying segments within words as correct or incorrect as it can obscure subtle underlying changes that may be occurring in speech production. They identified changes in lingual activity using ultrasound visual biofeedback therapy (U-VBF) which highlighted improvements in speech production not captured through categorical judgements such as those required to generate PCC scores. It might therefore be useful to look in further detail at EPG measures for each group at each time point and specifically at those phonemes targeted in therapy. Additional single-word EPG data was collected at all four time points which would lend itself to this type analysis and might provide more detail on accuracy and variability specific to therapy targets.

Probably the most surprising finding from this study concerned participants in Group 3 who were receiving no direct therapy as part of this study, yet made gains in speech production that appeared statistically, at least, similar to the other two groups. This group was intended to serve as a control for maturational change. Results of standardised assessments were shared with referring SLTs following initial assessment for all children to avoid a situation where tests with test-retest constraints were accidentally repeated. It is possible that this assessment report increased the focus on speech for participants which may have influenced intervention outside of the study.

It is generally accepted that if speech production can be improved then improvements in speech intelligibility will follow. In the current study, due to missing CSIM data at post-therapy time points in each group, it was impossible to investigate this relationship. However, on visual 
inspection of Figures 5 and 6, Group 1 and Group 2 (for which data were most complete) showed a different pattern of performance. For Group 1, there was a mirroring of performance on the two outcome measures, from pre-therapy to post-therapy and from 3-month posttherapy to 6-month post-therapy, with an overall gain in both PCC scores and CSIM scores from pre-therapy to 6-month post-therapy. However, in Group 2 the initial gain in PCC score was not reflected by gains in CSIM (which in fact decreased) although there was an overall gain for both measures when differences in post- therapy and 6-month post-therapy scores were calculated.

The difficulties of measuring intelligibility have been well documented (Miller 2013), specifically what people are referring to when using this term and how it might be assessed. The CSIM was chosen to measure intelligibility in this study for a number of reasons: it is easy to administer, provides a quantifiable measure of intelligibility, and scores can be directly compared across participants. The CSIM requires the SLT to select a word list at random from a choice of 200 lists and ask the participant to repeat the 50 words spoken by the SLT. An unfamiliar adult then listens to a recording of the 50 imitated words and identifies which word was spoken from 12 phonetically-similar words. For the participants in this study, all of whom presented with language impairment, the lists would have contained words which were unfamiliar to them and therefore the test, in parts, functionally became a measure of non-word repetition rather than a measure of intelligibility. Wild et al. (2018) believe that a single test cannot capture all aspects of intelligibility in DS due to many contributory factors. An approach adopting both analytic and subjective measures might provide more insights into intelligibility and also be capable of detecting any meaningful post-intervention change. A single-word identification test using simple consonant-vowel (CV), VC and CVC known target stimuli (as in Wild et al. 2018) presented both aurally and in pictorial and written format, could provide an objective measure of the child's speech whereas a parental questionnaire such as the Intelligibility in Context Scale (ICS: McLeod, Harrison and McCormack 2012), which uses an interval scale, could identify any change in the severity of the communication problem.

The purpose of any speech intervention study is to produce measurable gains in participants. An important design feature of this study was the requirement to assess changes in speech production not only post-therapy, but also 3- and 6-month post-therapy in order to investigate both the maintenance of any improvements and any further changes. Over the course of the study, measurable gains were made by children in all three groups: some gains were maintained, some furthered, and some lost over the 9 months of monitoring. Whilst changes in performance across and within groups did not always reach statistical significance, examination of individual changes in PCC scores revealed important differences in the groups that were not captured by the statistics. The findings from these qualitative analyses are encouraging and suggest further investigation with larger numbers is warranted. 


\section{CONCLUSION}

This research aimed to evaluate the effectiveness of EPG-based and EPG-informed therapy for improving speech production in 27 school-aged children with DS. By the very nature of the study, we started with a limited number of participants who demonstrated a variability in scores much greater than anticipated, with this in turn greatly decreasing our chances of identifying any statistically significant differences in performance over time. Perhaps Howard (1986) was right when he wrote, "it is not sensible to investigate the effects of a set of heterogeneous treatment techniques applied to a heterogeneous group of subjects measuring improvement with generalised and insensitive assessment techniques" (p.89). This notwithstanding, the qualitative analyses of individual gains presented here are encouraging and will hopefully stimulate further investigation of intervention techniques to improve the speech of individuals with DS. The results from this study, along with the findings from Terband et al. (2018), should be taken as evidence that individuals with DS can continue to improve their speech production and intelligibility into adolescence and adulthood. This should be reflected in future management plans and is paramount for full integration into communities, educational progress and improved employment prospects.

\section{ACKNOWLEDGEMENTS}

This research was supported by a grant from the UK Medical Research Council (G0401388). Thanks are extended to Dr Ann Robertson, Dr Diana Willis, Marie Down, Annabel Allen, Mae Douglas and Dr Ellie Drake for help with data collection and/or transcriptions; to Dr Stephen Corson for statistical advice; to Dr Roddy Nelson for orthodontic help; and to Down's Syndrome Scotland for helping with recruitment of participants. Special thanks are extended to the children, young people and their parents for their patience and dedication to this study.

\section{DECLARATION OF INTEREST}

The authors report no conflict of interest. The authors alone are responsible for the content and writing of the paper.

\section{REFERENCES}

BROOMFIELD, J., and DODD, B., 2011, Is speech and language therapy effective for children with speech/language impairment? A report of an RCT. International Journal of Language and Communication Disorder, 46, 628-40.

CARR J., 2008, The everyday life of adults with Down syndrome. Journal of Applied Research in Intellectual Disabilities, 21, 389-397. 
CHAPMAN, R.S., HESKETH, L.J. and KISTLER, D.J., 2002, Predicting longitudinal change in language production and comprehension in individuals with Down syndrome. Journal of Speech, Language, and Hearing Research, 45, 902-915.

CLELAND, J. and SCOBBIE, J.M., 2018, Acquisition of new speech motor plans via articulatory visual biofeedback. In S. Fuchs, J. Cleland, and A. Rochet-Cappelan (eds), Speech Production and Perception: Learning and Memory (Berlin: Peter Lang), (in press).

CLELAND, J., TIMMINS, C., WOOD, S., HARDCASTLE, W. and WISHART, J., 2009, Electropalatographic therapy for children and young people with Down's syndrome. Clinical Linguistics and Phonetics, 23, 926-939.

CLELAND, J., WOOD, S., HARDCASTLE, W., WISHART, J. and TIMMINS, C., 2010, Relationship between speech, oromotor, language and cognitive abilities in children with Down's syndrome. International Journal of Language and Communication Disorders, 45, 83-95.

DODD, B. and THOMPSON, L., 2001, Speech disorder in Down's syndrome. Journal of Intellectual Disability Research, 45, 308-316.

DODD, B., HUA, Z., CROSBIE, S. and HOLM, A., 2002, Diagnostic Evaluation of Articulation and Phonology (DEAP) (London: Psychological Corporation).

DUNN, L., DUNN, L., WHETTON, C. and BURLEY, J., 1997, British Picture Vocabulary ScaleSecond Edition (Windsor: NFER Nelson).

DYKE, P., LEONARD, H., BOURKE, J., BEBBINGTON, A., and BOWER, C., 2007, Down syndrome needs opinions wishes study report. [online] Available:

https://www.downsyndrome.org.au/documents/research/ds_NOW_report_2007.pdf [accessed 15 January 2018].

FAWCUS, S., BACSFALVI, P., and BERNHARDT, B.M. 2008, Ultrasound as visual feedback in speech therapy for / $r$ / in adults with Down syndrome. Down Syndrome Quarterly, 10, 4-12.

FIDLER, D.J. and NADEL, L., 2007, Education and children with Down syndrome: Neuroscience, development, and intervention. Developmental Disabilities Research Reviews, 13, 262-271.

GIBBON, F., 2013, Bibliography of Electropalatographic (EPG) studies in English (1957-2013). [online] Available: http://www.articulateinstruments.com/EPGrefs.pdf [accessed 31 January 2018].

GIBBON, F.E., MCNEILL, A.M., WOOD, S.E., \& WATSON, J.M.M., 2003, Changes in linguapalatal contact patterns during therapy for velar fronting in a 10-year-old with Down's syndrome. International Journal of Language and Communication Disorders, 38, 47-64. 
GIBBON, F.E. and WOOD, S.E., 2003, Using electropalatography (EPG) to diagnose and treat articulation disorders associated with mild cerebral palsy: a case study. Clinical Linguistics and Phonetics, 17, 365-374.

GIBBON, F.E. and WOOD, S.E., 2010, Visual feedback therapy with electropalatography (EPG) for speech sound disorders in children. In L. Williams, S. McLeod and R. McCauley (eds), Interventions in Speech Sound Disorders (Baltimore: Brookes), pp. 509-536.

GRIECO, J., PULSIFER, M., SELIGSOHN, K., SKOTKO, B. and SCHWARTZ, A., 2015, Down syndrome: cognitive and behavioural functioning across the lifespan. American Journal of Medical Genetics Part C: Seminars in Medical Genetics, 169, 135-149.

HAMILTON, C., 1993, Investigation of the articulatory patterns of young adults with Down's syndrome using electropalatography. Down Syndrome Research and Practice, 1, 15-28.

HITCHCOCK, E.R., HAREL, D, and MCALLISTER BYUN, T., 2015, Social, emotional and academic impact of residual speech errors in school-aged children: a survey study. Seminars in Speech and Language, 36, 283-294.

HITCHCOCK, E.R., MCALLISTER BYUN, T., SWARTZ, M. and LAZARUS, R., 2017, Efficacy of electropalatography for treating misarticulation of $/ r /$. American Journal of Speech-Language Pathology, 26, 1141-1158.

HOWARD, D., 1986. Evaluating intervention beyond randomised controlled trials: the case for effective case studies of the effects of treatment in aphasia. British Journal of Disorders of Communication, 21, 89-102.

JOFFE, V. and PRING, T., 2008, Children with phonological problems: a survey of clinical practice. International Journal of Language and Communication Disorders, 43, 154-164.

KENT, R. D. and VORPERIAN, H.K., 2013, Speech impairment in Down syndrome: A review. Journal of Speech, Language, and Hearing Research, 56, 178-210.

KUMIN, L., 2006, Speech intelligibility and childhood verbal apraxia in children with Down syndrome. Down Syndrome Research and Practice, 10, 10-22.

KUMIN, L., and SCHOENBRODT, L., 2016, Employment in adults with Down syndrome in the United States: Results from a national survey. Journal of Applied Research in Intellectual Disabilities, 29, 330-345.

MEYER, C., THEODOROS, D. and HICKSON, D., 2017, Management of swallowing and communication difficulties in Down syndrome: A survey of speech language pathologists. International Journal of Speech-Language Pathology, 19, 87-98. 
MCAULIFFE, M.J., ROBB, M.P. and MURDOCH, B.E., 2007, Acoustic and perceptual analysis of speech adaptation to an artificial palate. Clinical Linguistics and Phonetics, 21, 885-894.

MCLEOD, S., HARRISON, L.J. and MCCORMACK, J., 2012, The Intelligibility in Context Scale: validity and reliability of a subjective rating measure. Journal of Speech, Language and Hearing Research, 55, 648-656.

MILLER, N., 2013, Measuring up to speech intelligibility. International Journal of Language and Communication Disorders, 48, 601-612.

MURRAY, E., MCCABE, P. and BALLARD, K.J., 2015, A randomized controlled trial for children with childhood apraxia of speech comparing rapid syllable transition treatment and the Nuffield Dyspraxia Programme - Third Edition. Journal of Speech Language and Hearing Research, 58, 669-686.

NAESS, K.A., LYSTER, S.A., HULME, C. and MELBY-LERVAG, M., 2011, Language and verbal shortterm memory skills in children with Down syndrome: a meta-analytic review. Research in Developmental Disabilities, 32, 2225-2234.

NAMASIVAYAM, A.K., PUKONEN, M., GOSHULAK, D., YU, V.Y., KADIS, D.S., KROLL, R., PANG, E.W., and DE NIL, L.F., 2013, Relationship between speech motor control and speech intelligibility in children with speech sound disorders. Journal of Communication Disorders, 46, 264-280.

PRESTON, J. L., MAAS, E., WHITTLE, J., LEECE, M. C., and MCCABE, P., 2016, Limited acquisition and generalisation of rhotics with ultrasound visual feedback in childhood apraxia. Clinical Linguistics \& Phonetics, 30(3-5), 363-381.

RINGENBACH, S.D., MULVEY, G.M., CHEN, C.C. and JUNG, M.L., 2012, Unimanual and bimanual continuous movements benefit from visual instructions in persons with Down syndrome. Journal of Motor Behavior, 44, 233-239.

ROBBINS, J. and KLEE, T., 1987, Clinical assessment of oropharyngeal motor development in young children. Journal of Speech and Hearing Disorders, 52, 271-277.

ROBERTS, J., LONG, S.H., MALKIN, C., BARNES, E., SKINNER, M., HENNON, E.A. and ANDERSON, K. 2005, A comparison of phonological skills of boys with Fragile $X$ syndrome and Down syndrome. Journal of Speech, Language and Hearing Research, 48, 980-95.

ROBERTS, J., PRICE, J., BARNES, E., NELSON, L., BURCHINAL, M, HENNON, E.A. MOSKOWITZ, L., EDWARDS, A., MALKIN, C., ANDERSON, K., MISENHEIMER, J. and HOOPER, S.R., 2007, Receptive vocabulary, expressive vocabulary, and speech production of boys with Fragile $\mathrm{X}$ syndrome in 
comparison to boys with Down syndrome. American Journal of Mental Retardation, 112, 177193.

RUPELA, V., VELLEMAN, S.L. and ANDRIANOPOULOS, M.V., 2016, Motor speech skills in children with Down syndrome: A descriptive study. International Journal of Speech-Language Pathology, 18, 483-492.

RVACHEW, S. and FOLDEN, M., 2017, Speech therapy in adolescents with Down syndrome: In pursuit of communication as a fundamental human right. International Journal of SpeechLanguage Pathology. DOI · 10.1080/17549507.2018.1392605 (published on line 10 Nov 2017).

SOMMERS, R. K., PATTERSON, J. P., and WILDGEN, P. L., 1988, Phonology of Down syndrome speakers, ages 13-22. Communication Disorders Quarterly, 12, 65-91.

TERBAND, H., COPPENS-HOFMAN, M.C., REFFELTRATH, M. and MAASSEN, B.A., 2018, Effectiveness of speech therapy in adults with intellectual disabilities. Journal of Applied Research in Intellectual Disabilities, 31, 236-248.

WEISMER, G., YUNUSOVA, Y. and BUNTON, K., 2012, Measures to evaluate the effects of DBS on speech production. Journal of Neurolinguistics, 25, 74-94.

WECHSLER, D., 2003, Wechsler Primary and Preschool Scale of Intelligence - Third UK Edition (London: Psychological Corporation).

WIIG, E., SECORD, W. and SEMEL, E., 1992, Clinical Evaluation of Language Fundamentals Preschool UK (London: Psychological Corporation).

WILCOX, K. and MORRIS, S., 1999, Children's Speech Intelligibility Measure (CSIM) (London: Psychological Corporation).

WILD, A., VORPERIAN, H.K., KENT, R.D., BOLT, D.M. and AUSTIN, D., 2018, Single-word speech intelligibility in children and adults with Down syndrome. American Journal of SpeechLanguage Pathology, 27, 222-236.

WISHART, J.G., WILLIS, D.S., CEBULA, K.R. and PITCAIRN, T.K., 2007, Collaborative learning: comparison of outcomes for typically developing children and children with intellectual disabilities. American Journal on Mental Retardation, 112, 361-374.

WOOD, S.E. and HARDCASTLE, W.J., 2000, Instrumentation in the assessment and therapy of motor speech disorders: A survey of techniques and case studies with EPG. In I. Papathansiou (ed), Acquired Neurogenic Communication Disorders: A Clinical Perspective (London: Whurr), pp. $203-248$. 
WOOD, S.E., WISHART, J., HARDCASTLE, W.J., CLELAND, J. \& TIMMINS, C., 2009, The use of electropalatography in the assessment and treatment of motor speech disorders in children with Down's syndrome: evidence from two case studies. Developmental Neurorehabilitation, $12,66-75$.

WORLD HEALTH ORGANIZATION, 2018, Genes and human disease: Chromosomal diseases. [online] Available: http://www.who.int/genomics/public/geneticdiseases/en/index1.html [accessed 12 January 2018]. 